\title{
Effects of Different Concentrations of Poly(vinyl pyrrolidone) on the Solubility of Lamotrigine and Diazepam in Ethanol + Water Mixtures at 298.2 K
}

\author{
Shahla Soltanpour, ${ }^{\dagger}$ William E. Acree, Jr., ${ }^{\S}$ and Abolghasem Jouyban ${ }^{*}$, \\ Biotechnology Research Center and Faculty of Pharmacy and Drug Applied Research Center, Tabriz University (Medical \\ Sciences), Tabriz 51664, Iran, and Department of Chemistry, University of North Texas, Denton, Texas 76203-5070
}

\begin{abstract}
The effects of poly(vinyl pyrrolidone) K30 (PVP) (1) on the solubility of lamotrigine (2) and diazepam (2) at $298.2 \mathrm{~K}$ are reported for ethanol (3) + water (4) mixtures at five different concentrations $(0.0001,0.0005$, $0.001,0.005$ and 0.01$) \mathrm{g} \cdot \mathrm{mL}^{-1}$ of PVP. The general version of the Jouyban-Acree model was fitted to the solubility data of each drug in a given concentration of PVP. The largest mean relative deviation (MRD) was $14 \%$, that is, for diazepam in the presence of $(0.0005$ and 0.001$) \mathrm{g} \cdot \mathrm{mL}^{-1}$ of PVP, and the lowest MRD was $4 \%$ for lamotrigine in the presence of $0.01 \mathrm{~g} \cdot \mathrm{mL}^{-1}$ of PVP. The overall MRD for lamotrigine and diazepam was $9 \%$. A modified version of the Jouyban-Acree model was used to model the simultaneous effects of the ethanol and PVP on the solubility employing experimental solubility of drugs in water and ethanol in the absence of PVP. The MRDs for diazepam and lamotrigine were $23 \%$ and $10 \%$, respectively, with the overall value of $17 \%$.
\end{abstract}

\section{Introduction}

Knowledge of the solubility of drugs in the pharmaceutical fields is important because, it solves many problems involving chemical solution preparation and designing of liquid drug formulations. ${ }^{1}$ Poorly water-soluble drugs often exhibit inadequate or variable bioavailability, which limits their applicability in drug formulations. Nearly $40 \%$ of the drug candidates fail to proceed beyond the initial trial stages and never reach the marketplace because of low aqueous solubility. There are different methods for modifying drugs solubility such as oil formulations, complexation, salt formation, use of prodrugs, and cosolvency. ${ }^{1-6}$ The most common and easy-to-use method is cosolvency or addition of a cosolvent (permissible organic solvent) to the aqueous solution to alter the aqueous solubility. It should be noted that in the pharmaceutical industry the toxicity of the cosolvents is an important consideration and the cosolvent concentration should be kept as low as possible, especially in oral or injectable formulations. The method often used to optimize the solvent composition of solvent mixtures for dissolving a desired amount of a drug in a given volume of the solution is the trial-and-error approach, which is time-consuming and expensive.

In addition to the aforementioned methods for modifying the drug solubility, polymers are frequently used in the pharmaceutical industry to alter the solubility of drugs. ${ }^{7,8}$ Polymers decrease the gastrointestinal side effects, toxicity of drugs, ${ }^{9,10}$ or the dermal irritation of some skin products. ${ }^{11}$ Polymers could be employed in target therapy of cancers, ${ }^{12}$ masking of the unfavored taste of some drugs, avoidance of the fast elimination of drugs, production of the $\mathrm{pH}$ resistant formulations, ${ }^{13-15}$ and

\footnotetext{
* To whom correspondence should be addressed. E-mail: ajouyban@ hotmail.com. Fax: +98 4113363231.

$\dagger$ Biotechnology Research Center, Tabriz University (Medical Sciences)

Faculty of Pharmacy and Drug Applied Research Center, Tabriz University (Medical Sciences).

${ }^{\S}$ University of North Texas.
}

formulation of the injectable form of some drugs that cannot be formulated using common methods. ${ }^{16}$

Our past solubility studies have focused on developing mathematical equations to predict drug solubilities in aqueousorganic solvent mixtures. Predictive expressions are important in the early stages of drug discovery processes because one rarely has a sufficient quantity of the drug candidate to perform extensive solubility measurements. The models for representing the solubility of drugs in water-cosolvent mixtures and their advantages and limitations were recently reviewed. ${ }^{17}$ None of the models, however, considered the simultaneous effects of an organic cosolvent and a polymer additive.

Of the numerous models developed in recent years, the Jouyban-Acree model is perhaps one of the most versatile models. The model provides very accurate mathematical descriptions for how the solute solubility varies with both temperature and solvent composition. The model for representing the solubility of a solute in binary solvent mixture at various temperatures is

$$
\begin{aligned}
\log w_{2, m}^{\text {Sat }}=w_{3} \log w_{2,3}^{\text {Sat }}+w_{4} \log w_{2,4}^{\text {Sat }}+ & \\
& {\left[\frac{w_{3} w_{4}}{T / \mathrm{K}} \sum_{i=0}^{2} J_{i}\left(w_{3}-w_{4}\right)^{i}\right] }
\end{aligned}
$$

where $w_{2, m}^{\text {Sat }}$ is the solute mass fraction solubility in the mixtures at temperature $T, w_{3}$ and $w_{4}$ denote ethanol and water mass fractions in the absence of the solute and polymer, $w_{2,3}^{\text {Sat }}$ and $w_{2,4}^{\text {Sat }}$ denote the mass fraction solubility of the solute in the ethanol and water in the presence of polymer, respectively, and $J_{i}$ is the constant of the model computed by a regression analysis. ${ }^{17}$ Because it is clear in this form of the model, there is no parameter for showing the polymers effect on the solubility, so, we added the polymer mass fraction $\left(w_{1}\right)$ to the model. To represent the polymer concentration on the effective fraction of the solvents, we can subtract $w_{1}$ from the solvents fraction and the modified form of the model for representing the simultaneous effects of the cosolvent and polymer is 


$$
\begin{array}{r}
\log w_{2, m}^{\mathrm{Sat}}=\left(w_{3}-w_{1}\right) \log w_{2,3}^{\mathrm{Sat}, w_{1}=0}+ \\
\left(w_{4}-w_{1}\right) \log C_{2,4}^{\mathrm{Sat}, w_{1}=0}+\left[\frac{\left(w_{3}-w_{1}\right)\left(w_{4}-w_{1}\right)}{T / \mathrm{K}} \times\right. \\
\left.\sum_{i=0}^{2} A_{i}\left\{\left(w_{3}-w_{1}\right)-\left(w_{4}-w_{1}\right)\right\}^{i}\right]
\end{array}
$$

where $w_{2,3}^{\text {Sat, } w_{1}=0}$ and $w_{2,4}^{\text {Sat, }, w_{1}=0}$ are the mass fraction solubilities of the solute in the neat ethanol and water in the absence of polymer $\left(w_{1}=0\right)$ at temperature $T$ taken from a previous work, ${ }^{18}$ so we do not need to measure the drug solubility in pure solvents in the presence of PVP, and $A_{i}$ is the model constant. Because $w_{3}, w_{4}, w_{1}, \log w_{2,3}^{\mathrm{Sat}, w_{1}=0}$, and $\log w_{2,3}^{\mathrm{Sat}, w_{1}=0}$ are dimensionless quantities and $T$ is the only variable with the unit of $\mathrm{K}$, the $A_{i}$ terms should take the unit of $\mathrm{K}^{-1}$.

Experimental solubilities of several antiepileptic drugs in ethanol + water mixtures in the absence of polymer were reported in a previous work. ${ }^{18}$ In this work, the experimental solubility of lamotrigine and diazepam in ethanol + water mixtures in the presence of three different concentrations of poly(vinyl pyrrolidone) K30 (PVP) at $298.2 \mathrm{~K}$ are reported. In addition, the applicability of the Jouyban-Acree model to the measured solubility of drugs in ethanol + water mixtures in the presence of PVP was investigated.

\section{Experimental Method}

Materials. Lamotrigine was purchased from Arastoo pharmaceutical company (Iran), and diazepam was purchased from Sobhan pharmaceutical company (Iran). The purity of both drugs was checked by melting point determination and by comparing the measured solubilities in monosolvents with the corresponding data from the literature. ${ }^{19-22}$ Ethanol $(99.5 \%)$ was purchased from Merck (Germany), PVP (with the water content of $4.2 \%$ and approximate molecular weight of 40000 ) was a gift from Daana pharmaceutical company (Iran), and doubledistilled water was used for the preparation of the solutions.

Apparatus and Procedures. We prepared the binary solvent mixtures by mixing the appropriate volumes of the solvents with the uncertainty of 0.001 volume fraction. PVP $((0.01,0.05,0.1$, 0.5 , and 1) g) was added to $100 \mathrm{~mL}$ of the binary solvent mixtures, and $w_{1}$ was calculated using the mass fractions of water, ethanol, and PVP in the absence of the solutes. The solubilities of lamotrigine and diazepam in ethanol + water mixtures were previously reported. ${ }^{18}$ We determined the solubility of lamotrigine and diazepam in the presence of five different concentrations $\left(w_{1}\right)$ of PVP in ethanol + water mixtures by equilibrating an excess amount of drug at $298.2 \mathrm{~K}$ using a shaker (Behdad, Tehran, Iran) placed in an incubator equipped with a temperature-controlling system maintained constant within \pm $0.2 \mathrm{~K}$. After a sufficient length of time $(>72 \mathrm{~h})$, the saturated solutions of the drugs were centrifuged at $12000 \mathrm{rpm}$ for 7 min, diluted with water, and then assayed at (306 and 250) nm, respectively, using a UV-vis spectrophotometer (Beckman DU650 , Fullerton). Concentrations of the diluted solutions were determined from the calibration curves. Details of calibration curves are given in Table 1. Each experimental data point represents the average of at least three repetitive experiments with the measured solubilities being reproducible to within \pm $3.3 \%$. Calculated standard deviations of $\mathrm{mol} \cdot \mathrm{L}^{-1}$ solubilities ranged from $\sigma_{n-1}=0.00001$ to 0.01239 .

Computational Methods. The experimental solubility data of each drug in the binary solvents and a given concentration of PVP were regressed in accordance to eq 1 , and the backcalculated solubilities were used to calculate the accuracy of the derived mathematical correlation. In the next analysis, we fitted eq 2 to the solubility of each drug in binary solvents with different concentrations of PVP $((0,0.0001,0.0005,0.001$, 0.005 , and 0.01$) \mathrm{g} \cdot \mathrm{mL}^{-1}$ ) by employing the experimental solubilities of drugs in neat ethanol and water taken from a previous work. ${ }^{18}$ The mass fraction solubility is calculated using $w_{2}=$

grams of solute
grams of PVP + grams of solute + grams of ethanol +
grams of water

The mean relative deviation (MRD) was used to check the accuracy of the numerical methods and is calculated using

$$
\operatorname{MRD}=\frac{\sum\left\{\frac{\left|\left(w_{2, m}^{\text {Sat }}\right)_{\text {calculated }}-\left(w_{2, m}^{\text {Sat }}\right)\right|}{\left(w_{2, m}^{\text {Sat }}\right)}\right\}}{N}
$$

where $N$ is the number of data points in each set. All computations were carried out using SPSS.

\section{Results and Discussion}

Tables 2 and 3 list the experimental solubilities of diazepam and lamotrigine in ethanol + water mixtures in the presence of five concentrations of PVP at $298.2 \mathrm{~K}$. We increased the solubility of lamotrigine in water by increasing the PVP concentration, which is in agreement with previous findings. ${ }^{23-26}$ There is no significant change in the aqueous solubility of diazepam and ethanolic solubility of lamotrigine in the presence of various concentrations of PVP; however, the ethanolic solubility of diazepam and aqueous solubility of lamotrigine are increased with the increased concentration of PVP. The increased solubility reveals that there is an interaction between drugs and PVP in the solution. ${ }^{23,25}$ The addition of PVP to ethanol + water did not affect the solubility of lamotrigine, and there is no systematic pattern for lamotrigine solubilities in ethanol + water mixtures in the presence of PVP. Diazepam solubilities were increased with an increase in PVP concentrations in the ethanol-rich region of solvent mixtures. The numerical values of the constants $J_{0}-J_{2}$, and $A_{0}-A_{2}$ for two drugs and the OMRD values for two methods are summarized in Table 4.

The Jouyban-Acree model provided a reasonably accurate mathematical description of the experimental solubility data of both drug molecules over the entire binary solvent composition range. This finding is also supported by small MRD values of

\begin{tabular}{|c|c|c|c|c|}
\hline & $\varepsilon$ & $C$ & & \\
\hline drug & $\mathrm{L} \cdot \mathrm{mol}^{-1} \cdot \mathrm{cm}^{-1}$ & $\mathrm{~mol} \cdot \mathrm{L}^{-1}$ & correlation coefficient (standard error) & calibration curve ( $A$ : absorbance) \\
\hline lamotrigine & 8283 to 8597 & $2.2 \cdot 10^{-5}$ to $6.6 \cdot 10^{-5}$ & $0.999(0.001)$ & $A=8136.9 C+0.0102$ \\
\hline diazepam & 10835 to 11454 & $2.2 \cdot 10^{-5}$ to $6.7 \cdot 10^{-5}$ & $0.998(0.018)$ & $A=11637.0 C-0.0201$ \\
\hline
\end{tabular}
the back-calculated and experimental solubility data. The main limitation of eq 1 is that it must be trained for each drug

Table 1. Details of Calibration Curves of Drugs 
Table 2. Experimental Mole per Liter $\left(\mathrm{C}_{m}^{\mathrm{Sat}}\right)$ and Mass Fraction $\left(w_{2, m}^{\text {Sat }}\right)$ Solubilities of Diazepam (2) in Ethanol (3) + Water (4) Mixtures in the Presence of Various Concentrations of Poly(vinyl pyrrolidone) (1) Expressed as the Mass Fraction of PVP $\left(w_{1}\right)$ at 298.2 $\mathrm{K}$ and Their Standard Deviations $(N=3)$

\begin{tabular}{|c|c|c|c|}
\hline \multirow[b]{2}{*}{$w_{3}$} & \multirow[b]{2}{*}{$w_{1}$} & $C_{m}^{\text {Sat }}$ & \multirow[b]{2}{*}{$w_{2, m}^{\text {Sat }}$} \\
\hline & & $\mathrm{mol} \cdot \mathrm{L}^{-1}$ & \\
\hline \multicolumn{4}{|c|}{$\left(\mathrm{PVP} 0.0001 \mathrm{~g} \cdot \mathrm{mL}^{-1}\right)$} \\
\hline 0.0000 & 0.0001 & $0.0001(0.0000)^{a}$ & 0.00003 \\
\hline 0.0806 & 0.0001 & $0.0004(0.0000)^{a}$ & 0.00012 \\
\hline 0.1648 & 0.0001 & $0.0009(0.0000)^{a}$ & 0.00027 \\
\hline 0.2527 & 0.0001 & $0.0022(0.0001)$ & 0.00067 \\
\hline 0.3447 & 0.0001 & $0.0133(0.0005)$ & 0.00412 \\
\hline 0.4410 & 0.0001 & $0.0316(0.0007)$ & 0.00996 \\
\hline 0.5420 & 0.0001 & $0.0678(0.0011)$ & 0.02162 \\
\hline 0.6480 & 0.0001 & $0.0980(0.0017)$ & 0.03169 \\
\hline 0.7594 & 0.0001 & $0.1272(0.0124)$ & 0.04174 \\
\hline 0.8766 & 0.0001 & $0.1284(0.0087)$ & 0.04317 \\
\hline 1.000 & 0.0001 & $0.1169(0.0069)$ & 0.04047 \\
\hline \multicolumn{4}{|c|}{$\left(\mathrm{PVP} 0.0005 \mathrm{~g} \cdot \mathrm{mL}^{-1}\right)$} \\
\hline 0.0000 & 0.0005 & $0.0001(0.0000)^{a}$ & 0.00003 \\
\hline 0.0806 & 0.0005 & $0.0004(0.0000)^{a}$ & 0.00012 \\
\hline 0.1648 & 0.0005 & $0.0009(0.0000)^{a}$ & 0.00027 \\
\hline 0.2527 & 0.0005 & $0.0020(0.0000)^{a}$ & 0.00061 \\
\hline 0.3447 & 0.0005 & $0.0138(0.0005)$ & 0.00427 \\
\hline 0.4410 & 0.0006 & $0.0320(0.0007)$ & 0.01008 \\
\hline 0.5420 & 0.0006 & $0.0690(0.0016)$ & 0.02198 \\
\hline 0.6480 & 0.0006 & $0.0990(0.0016)$ & 0.03199 \\
\hline 0.7594 & 0.0006 & $0.1315(0.0023)$ & 0.04307 \\
\hline 0.8766 & 0.0006 & $0.1470(0.0051)$ & 0.04909 \\
\hline 1.000 & 0.0006 & $0.1332(0.0033)$ & 0.04583 \\
\hline \multicolumn{4}{|c|}{$\left(\right.$ PVP $\left.0.001 \mathrm{~g} \cdot \mathrm{mL}^{-1}\right)$} \\
\hline 0.0000 & 0.0010 & $0.0001(0.0000)^{a}$ & 0.00003 \\
\hline 0.0806 & 0.0010 & $0.0004(0.0000)^{a}$ & 0.00012 \\
\hline 0.1648 & 0.0010 & $0.0009(0.0000)^{a}$ & 0.00027 \\
\hline 0.2527 & 0.0011 & $0.0022(0.0000)^{a}$ & 0.00067 \\
\hline 0.3447 & 0.0011 & $0.0143(0.0002)$ & 0.00442 \\
\hline 0.4410 & 0.0011 & $0.0333(0.0012)$ & 0.01048 \\
\hline 0.5420 & 0.0011 & $0.0720(0.0029)$ & 0.02291 \\
\hline 0.6480 & 0.0011 & $0.1037(0.0050)$ & 0.03344 \\
\hline 0.7594 & 0.0011 & $0.1421(0.0040)$ & 0.04636 \\
\hline 0.8766 & 0.0012 & $0.1708(0.0087)$ & 0.05656 \\
\hline 1.000 & 0.0012 & $0.1547(0.0034)$ & 0.05281 \\
\hline \multicolumn{4}{|c|}{$\left(\mathrm{PVP} 0.005 \mathrm{~g} \cdot \mathrm{mL}^{-1}\right)$} \\
\hline 0.0000 & 0.0050 & $0.0002(0.0000)^{a}$ & 0.00006 \\
\hline 0.0806 & 0.0051 & $0.0005(0.0000)^{a}$ & 0.00014 \\
\hline 0.1648 & 0.0052 & $0.0009(0.0000)^{a}$ & 0.00027 \\
\hline 0.2527 & 0.0053 & $0.0023(0.0000)^{a}$ & 0.00069 \\
\hline 0.3447 & 0.0054 & $0.0145(0.0005)$ & 0.00446 \\
\hline 0.4410 & 0.0055 & $0.0320(0.0007)$ & 0.01003 \\
\hline 0.5420 & 0.0056 & $0.0710(0.0016)$ & 0.02249 \\
\hline 0.6480 & 0.0056 & $0.1045(0.0016)$ & 0.03354 \\
\hline 0.7594 & 0.0057 & $0.1545(0.0023)$ & 0.04997 \\
\hline 0.8766 & 0.0058 & $0.1823(0.0051)$ & 0.05986 \\
\hline 1.000 & 0.0059 & $0.1684(0.0033)$ & 0.05694 \\
\hline \multicolumn{4}{|c|}{$\left(\mathrm{PVP} 0.01 \mathrm{~g} \cdot \mathrm{mL}^{-1}\right)$} \\
\hline 0.0000 & 0.0099 & $0.0002(0.0000)^{a}$ & 0.00006 \\
\hline 0.0806 & 0.0101 & $0.0005(0.0000)^{a}$ & 0.00014 \\
\hline 0.1648 & 0.0103 & $0.0010(0.0000)^{a}$ & 0.00029 \\
\hline 0.2527 & 0.0106 & $0.0023(0.0001)$ & 0.00069 \\
\hline 0.3447 & 0.0108 & $0.0147(0.0004)$ & 0.00450 \\
\hline 0.4410 & 0.0109 & $0.0311(0.0007)$ & 0.00969 \\
\hline 0.5420 & 0.0111 & $0.0699(0.0021)$ & 0.02203 \\
\hline 0.6480 & 0.0112 & $0.1066(0.0034)$ & 0.03400 \\
\hline 0.7594 & 0.0113 & $0.1639(0.0072)$ & 0.05256 \\
\hline 0.8766 & 0.0114 & $0.1925(0.0103)$ & 0.06264 \\
\hline 1.000 & 0.0118 & $0.1811(0.0087)$ & 0.06062 \\
\hline
\end{tabular}

\footnotetext{
${ }^{a}$ Standard deviation is less than 0.00005 .
}

Table 3. Experimental Mole per Liter $\left(\mathrm{C}_{m}^{\mathrm{Sat}}\right)$ and Mass Fraction $\left(w_{2, m}^{\text {Sat }}\right)$ Solubilities of Lamotrigine (2) in Ethanol (3) + Water (4) Mixtures in the Presence of Various Concentrations of Poly(vinyl pyrrolidone) (1) Expressed as the Mass Fraction of PVP $\left(w_{1}\right)$ at 298.2 $\mathrm{K}$ and Their Standard Deviations $(N=3)$

\begin{tabular}{cccc}
\hline & \multicolumn{2}{c}{$C_{m}^{\mathrm{Sat}}$} \\
$w_{3}$ & $w_{1}$ & $\mathrm{~mol} \cdot \mathrm{L}^{-1}$ & $w_{2, m}^{\mathrm{Sat}}$ \\
\hline \multicolumn{4}{c}{$\left(\mathrm{PVP} 0.0001 \mathrm{~g} \cdot \mathrm{mL}^{-1}\right)$} \\
0.0000 & 0.0001 & $0.0012(0.0001)$ & 0.00031 \\
0.0806 & 0.0001 & $0.0013(0.0000)^{a}$ & 0.00034 \\
0.1648 & 0.0001 & $0.0025(0.0000)^{a}$ & 0.00067 \\
0.2527 & 0.0001 & $0.0049(0.0000)^{a}$ & 0.00134 \\
0.3447 & 0.0001 & $0.0107(0.0004)$ & 0.00298 \\
0.4410 & 0.0001 & $0.0189(0.0007)$ & 0.00538 \\
0.5420 & 0.0001 & $0.0328(0.0007)$ & 0.00952 \\
0.6480 & 0.0001 & $0.0398(0.0009)$ & 0.01182 \\
0.7594 & 0.0001 & $0.0391(0.0025)$ & 0.01190 \\
0.8766 & 0.0001 & $0.0330(0.0017)$ & 0.01032 \\
1.000 & 0.0001 & $0.0137(0.0004)$ & 0.00443
\end{tabular}

0.0000

0.0806

0.1648

0.2527

0.3447

0.4410

0.5420

0.6480

0.7594

0.8766

1.000

0.0000

0.0806

0.1648

0.2527

0.3447

0.4410

0.5420

0.6480

0.7594

0.8766

1.000

0.0000

0.0806

0.1648

0.2527

0.3447

0.4410

0.5420

0.6480

0.7594

0.8766

1.000

0.0000

0.0806

0.1648

0.2527

0.3447

0.4410

0.5420

0.6480

0.7594

0.8766

1.000

$\left(\mathrm{PVP} 0.0005 \mathrm{~g} \cdot \mathrm{mL}^{-1}\right)$

$\begin{array}{lll}0.0005 & 0.0012(0.0001) & 0.00031 \\ 0.0005 & 0.0013(0.0000) & 0.00034 \\ 0.0005 & 0.0025(0.0001) & 0.00067 \\ 0.0005 & 0.0049(0.0001) & 0.00134 \\ 0.0005 & 0.0111(0.0001) & 0.00309 \\ 0.0006 & 0.0192(0.0003) & 0.00546 \\ 0.0006 & 0.0334(0.0006) & 0.00969 \\ 0.0006 & 0.0400(0.0007) & 0.01187 \\ 0.0006 & 0.0397(0.0016) & 0.01208 \\ 0.0006 & 0.0330(0.0021) & 0.01032 \\ 0.0006 & 0.0140(0.0006) & 0.00452\end{array}$

(PVP $\left.0.001 \mathrm{~g} \cdot \mathrm{mL}^{-1}\right)$

$\begin{array}{lll}0.0010 & 0.0013(0.0000)^{a} & 0.00033 \\ 0.0010 & 0.0014(0.0001) & 0.00037 \\ 0.0010 & 0.0026(0.0001) & 0.00069 \\ 0.0011 & 0.0051(0.0002) & 0.00139 \\ 0.0011 & 0.0118(0.0004) & 0.00329 \\ 0.0011 & 0.0206(0.0004) & 0.00586 \\ 0.0011 & 0.0342(0.0003) & 0.00992 \\ 0.0012 & 0.0403(0.0022) & 0.01195 \\ 0.0012 & 0.0403(0.0010) & 0.01225 \\ 0.0012 & 0.0338(0.0006) & 0.01056 \\ 0.0013 & 0.0144(0.0002) & 0.00465\end{array}$

\begin{tabular}{lrl}
\multicolumn{2}{c}{$\left(\mathrm{PVP} 0.005 \mathrm{~g} \cdot \mathrm{mL}^{-1}\right)$} & \\
0.0050 & $0.0015(0.0001)$ & 0.00038 \\
0.0051 & $0.0016(0.0001)$ & 0.00042 \\
0.0052 & $0.0028(0.0001)$ & 0.00074 \\
0.0053 & $0.0052(0.0001)$ & 0.00141 \\
0.0054 & $0.0118(0.0004)$ & 0.00327 \\
0.0055 & $0.0209(0.0008)$ & 0.00592 \\
0.0056 & $0.0340(0.0006)$ & 0.00982 \\
0.0058 & $0.0410(0.0009)$ & 0.01210 \\
0.0059 & $0.0409(0.0004)$ & 0.01237 \\
0.0061 & $0.0340(0.0006)$ & 0.01057 \\
0.0063 & $0.0148(0.0006)$ & 0.00475
\end{tabular}

0.0063

$$
\left(\mathrm{PVP} 0.01 \mathrm{~g} \cdot \mathrm{mL}^{-1}\right)
$$

$\begin{array}{lll}0.0099 & 0.0019(0.0000)^{a} & 0.00048 \\ 0.0101 & 0.0021(0.0001) & 0.00054 \\ 0.0103 & 0.0032(0.0001) & 0.00085 \\ 0.0105 & 0.0056(0.0002) & 0.00151 \\ 0.0108 & 0.0122(0.0004) & 0.00336 \\ 0.0110 & 0.0214(0.0002) & 0.00602 \\ 0.0112 & 0.0350(0.0004) & 0.01004 \\ 0.0115 & 0.0423(0.0018) & 0.01241 \\ 0.0117 & 0.0409(0.0020) & 0.01230 \\ 0.0121 & 0.0347(0.0009) & 0.01072 \\ 0.0125 & 0.0156(0.0005) & 0.00498\end{array}$

${ }^{a}$ Standard deviation is less than 0.00005 . employing a minimum number of experimental data in binary solvents. The predicted solubilities were compared with the corresponding experimental data, and MRD values were computed and listed in Table 4. The Jouyban-Acree model also described the experimental solubility behavior of drugs in binary solvents with given concentrations of PVP; however, there is no possibility of predicting the solubilities at other PVP concentration. To address this limitation, we modified the model 
Table 4. Model Constants and the Mean Relative Deviations (MRDs) for Equations 1 and 2

\begin{tabular}{|c|c|c|c|c|c|}
\hline & & $J_{0}$ & $J_{1}$ & $J_{2}$ & $\begin{array}{l}100^{\circ} \\
\text { MRD }\end{array}$ \\
\hline \multicolumn{6}{|c|}{ eq 1} \\
\hline diazepam, PVP $0.0001 \mathrm{~g} \cdot$ & $\mathrm{L}^{-1}$ & 1367.761 & 122.963 & -625.316 & 12 \\
\hline diazepam, PVP $0.0005 \mathrm{~g}$. & $\mathrm{L}^{-1}$ & 1337.608 & 131.372 & -625.236 & 14 \\
\hline diazepam, PVP $0.001 \mathrm{~g} \cdot \mathrm{n}$ & & 1322.451 & 112.143 & -595.533 & 14 \\
\hline diazepam, PVP $0.005 \mathrm{~g} \cdot \mathrm{n}$ & & 1129.298 & 394.904 & -906.123 & 12 \\
\hline diazepam, PVP $0.01 \mathrm{~g} \cdot \mathrm{m}$ & & 1103.753 & 383.111 & -821.901 & 12 \\
\hline lamotrigine, PVP 0.0001 & $\mathrm{~mL}^{-1}$ & 976.508 & 684.658 & -476.350 & 6 \\
\hline lamotrigine, PVP 0.0005 & $\mathrm{~mL}^{-1}$ & 981.811 & 674.782 & -503.985 & 6 \\
\hline lamotrigine, PVP $0.001 \mathrm{~g}$ & $\mathrm{~nL}^{-1}$ & 978.490 & 659.969 & -524.487 & 6 \\
\hline lamotrigine, PVP $0.005 \mathrm{~g}$ & $\mathrm{~nL}^{-1}$ & 933.205 & 682.477 & -512.097 & 5 \\
\hline lamotrigine, PVP $0.01 \mathrm{~g} \cdot 1$ & $\mathrm{~L}^{-1}$ & 863.693 & 687.197 & -478.059 & 4 \\
\hline & & & & overall MRD: & 9 \\
\hline \multicolumn{6}{|c|}{$A_{0}$} \\
\hline \multicolumn{6}{|c|}{ eq 2} \\
\hline diazepam $(N=66)^{a}$ & \multirow{2}{*}{\multicolumn{2}{|c|}{$\begin{array}{l}1218.161 \\
1093.329\end{array}$}} & 12.608 & \multirow{2}{*}{$\frac{-766.472}{b}$} & 23 \\
\hline \multirow[t]{2}{*}{ lamotrigine $(N=66)^{a}$} & & & 29.962 & & 10 \\
\hline & \multicolumn{2}{|c|}{1093.329} & & overall MRD: & 17 \\
\hline
\end{tabular}

${ }^{a}$ Solubility data of diazepam and lamotrigine in ethanol + water mixtures in the absence of $\mathrm{PVP}^{18}$ were also included in this numerical analysis. ${ }^{b}$ Not significant.

to include provisions for varying the concentration of PVP. Our proposed modification, eq 2, was found to provide reasonable results for two investigated solubility sets. Back-calculated solubilities of diazepam and lamotrigine produced the MRDs of $23 \%$ and $10 \%(N=66)$. When eq 2 is trained for a given drug in ethanol + water mixtures in the presence of a given polymer, it could be used to predict the unmeasured solubilities in the presence of different concentrations of the polymer using interpolation technique. To show the accuracy of this capability, the model was trained for diazepam and lamotrigine using the solubility data in the presence of $(0.0001$ and 0.01$) \mathrm{g} \cdot \mathrm{mL}^{-1}$ of PVP, and the solubilities of the drugs in the presence of $(0.001$, 0.005 , and 0.0005$) \mathrm{g} \cdot \mathrm{mL}^{-1}$ of PVP were predicted and then compared with the corresponding experimental values in which the MRDs were $24 \%$ and $10 \%$, respectively, for diazepam and lamotrigine. The modification does need to be further validated with additional experimental data for other drug molecules and other polymer additives. In general, the overall MRDs observed in these predictions show that the modified version of the Jouyban-Acree model provided more accurate predictions in the presence of an organic cosolvent and polymer additive. To our knowledge, no other predictive model has been suggested for covering these two parameters simultaneously on the solubility of drugs.

\section{Acknowledgment}

We would like to thank Sobhan, Arastoo, and Daana pharmaceutical companies for supplying the drug powders.

\section{Literature Cited}

(1) Dressman, J.; Reppas, C. Drug Solubility: How to Measure it, How to Improve it. Adv. Drug Delivery Rev. 2007, 59, 531-532.

(2) Serajuddin, A. T. M. Salt Formation to Improve Drug Solubility. Adv. Drug Delivery Rev. 2007, 59, 603-616.

(3) Blagden, N.; de Matas, M.; Gavan, P. T.; York, P. Crystal Engineering of Active Pharmaceutical Ingredients to Improve Solubility and Dissolution Rates. Adv. Drug Delivery Rev. 2007, 59, 617-630.
(4) Brewster, M. E.; Loftsson, T. Cyclodextrins as Pharmaceutical Solubilizers. Adv. Drug Delivery Rev. 2007, 59, 645-666.

(5) Hauss, D. J. Oral Lipid-Based Formulations. Adv. Drug Delivery Rev. 2007, 59, 667-676.

(6) Stella, V. J.; Nti-Addae, K. W. Prodrug Strategies to Overcome Poor Water Solubility. Adv. Drug Delivery Rev. 2007, 59, 677-694.

(7) Marsac, P. J.; Li, T.; Taylor, L. S. Estimation of Drug-Polymer Miscibility and Solubility in Amorphous Solid Dispersions Using Experimentally Determined Interaction Parameters. Pharm. Res. 2009, 26, $1-13$.

(8) Ribeiro, L.; Viga, F. Complexation of Vinpocetine with Cyclodextrins in the Presence or Absence of Polymers. Binary and Ternary Complexes Preparation and Characterization. J. Inclusion Phenom. Macrocyclic Chem. 2002, 44, 251-256.

(9) Haznedar, S.; Dortunc, B. Preparation and in Vitro Evaluation of Eudragit Microspheres Containing Acetazolamide. Int. J. Pharm. 2004, 269, 131-140.

(10) Verdun, C.; Couvreur, P.; Vranckx, H.; Lenaerts, V.; Roland, M. Development of a Nanoparticle Controlled-Release Formulation for Human Use. J. Controlled Release 1986, 3, 205-510.

(11) Shinkai, N.; Korenaga, K.; Mizu, H.; Yamauchi, H. Intra-Articular Penetration of Ketoprofen and Analgesic Effects after Topical Patch Application in Rats. J. Controlled Release 2008, 131, 107-112.

(12) Chono, S.; Li, S. D.; Conwell, C. C.; Huang, L. An Efficient and Low Immunostimulatory Nanoparticle Formulation for Systemic siRNA Delivery to the Tumor. J. Controlled Release 2008, 131, 64-69.

(13) Oren, P. L.; Seidler, W. M. K. Sustained Release Matrix. U.S. Patent 4,968,508, November 6, 1990 .

(14) Streubel, A.; Siepmann, J.; Dashevsky, A.; Bodmeier, R. pHindependent Release of a Weakly Basic Drug from Water-Insoluble and -Soluble Matrix Tablets. J. Controlled Release 2000, 67, 101110.

(15) Timmins, P.; Delargy, A. M.; Howard, J. R. Optimization and Characterization of a pH-Independent Extended-Release Hydrophilic Matrix Tablet. Pharm. Dev. Technol. 1997, 2, 25-31.

(16) McHugh, A. J.; Desnoyer, J. R.; Raman, C. Injectable Drug Delivery Based on Polymer Solutions: Experiment and Modeling. ACS Symp. Ser. 2008, 924, 14-28.

(17) Jouyban, A. Review of the Cosolvency Models for Predicting Solubility of Drugs in Water-Cosolvent Mixtures. J. Pharm. Pharm. Sci. 2008, $11,32-58$.

(18) Shayanfar, A.; Fakhree, M. A. A.; Acree Jr, W. E.; Jouyban, A. Solubility of Lamotrigine, Diazepam, and Clonazepam in Ethanol + Water Mixtures at 298.15 K. J. Chem. Eng. Data 2009, 54, 11071109.

(19) Moffat, A. C. Clarke's Analysis of Drug and Poisons; Pharmaceutical Press: London, 2004.

(20) Loftsson, T.; Hreinsdoìttir, D. Determination of Aqueous Solubility by Heating and Equilibration: A Technical Note. AAPS Pharm. Sci. Tech. 2006, 7, e1-e4.

(21) Florey, K. Analytical Profiles of Drug Substances; Academic Press: New York, 1977; Vol. 6, p 70.

(22) LlinaÌs, A.; Glen, R. C.; Goodman, J. M. Solubility Challenge: Can You Predict Solubilities of 32 Molecules Using a Database of 100 Reliable Measurements? J. Chem. Inf. Model 2008, 48, 1289-1303.

(23) Mura, P.; Faucci, M. T.; Bettinetti, G. P. The Influence of Polyvinylpyrrolidone on Naproxen Complexation with Hydroxypropyl- $\beta$ cyclodextrin. Eur. J. Pharm. Sci. 2001, 13, 187-194.

(24) Laitinen, R.; Suihko, E.; Toukola, K.; Bjorkqvist, M.; Riikonen, J.; Lehto, V. P.; Jarvinen, K.; Ketolainen, J. Intraorally Fast-Dissolving Particles of a Poorly Soluble Drug: Preparation and in Vitro Characterization. Eur. J. Pharm. Biopharm 2009, 71, 271-281.

(25) Chowdary, K. P. R.; Srinivas, S. V. Influence of Hydrophilic Polymers on Celecoxib Complexation with Hydroxypropyl- $\beta$-cyclodextrin. AAPS Pharm. Sci. Tech. 2006, 7, E1-E6.

(26) Liu, C.; Desai, K. G. H.; Liu, C. Solubility of Rofecoxib in the Presence of Mannitol, Poly(vinylpyrrolidone) K30, Urea, Polyethylene Glycol 4000, and Polyethylene Glycol 6000 at $(298.15,303.15$, and 308.15) K. J. Chem. Eng. Data 2005, 50, 661-665.

Received for review April 21, 2009. Accepted July 13, 2009. We thank the Drug Applied Research Center for the financial support.

JE900369W 